\title{
Cycles of violence in England and Wales: the contribution of childhood abuse to risk of violence revictimisation in adulthood
}

\author{
Nadia Butler ${ }^{1 *}$, Zara Quigg ${ }^{1}$ and Mark A. Bellis ${ }^{2,3}$
}

\begin{abstract}
Background: Interpersonal violence is a leading cause of death and disability globally, has immediate and longterm impacts on individuals' health and wellbeing, and impacts global health care expenditures and national economies. A public health approach to violence prevention is crucial, and addressing risk factors is a key priority. Global research has demonstrated that childhood adversity increases risk of a range of poor outcomes across the lifecourse. This study examined the association between being a victim of child abuse and the risk of physical assault (PA), intimate partner violence (IPV), and sexual violence (SV) victimisation in adulthood.
\end{abstract}

Methods: Data from a nationally representative survey of household residents (adults aged 16 to 59 years; $n=21,845$ ) was analysed. Types of child abuse examined included physical, sexual, and psychological abuse and witnessing domestic violence. Logistic regressions examined the independent relationships between child abuse types, experiencing multiple types, and adulthood violence outcomes.

Results: Most individual types of child abuse were significantly associated with each adulthood violence outcome, after controlling for sociodemographics and other abuse types. Compared to individuals who experienced no abuse in childhood, those who experienced one form of abuse were over twice as likely to experience PA in the past year and three times as likely to have experienced IPV and/or SV since age 16 years, whilst individuals who experienced multiple types were three, six, and seven times more likely to experience PA, IPV, and SV, respectively. After controlling for sociodemographics and multi-type childhood victimisation, the type or combination of types which remained significant differed by violence outcome; child psychological and physical abuse were significantly associated with IPV; psychological and sexual abuse with SV; and psychological abuse with PA.

Conclusions: Prevention of child abuse is an important goal, and evidence from the current study suggests such efforts will have a downstream effect on preventing interpersonal violence across the lifecourse. With adulthood victimisation likely to compound the already detrimental effects of childhood abuse, and given that many associated outcomes also represent adversities for the next generation, breaking the cycle of violence should be a public health priority.

Keywords: Child abuse, Intimate partner violence, Sexual violence, Physical assault, Revictimisation

\footnotetext{
* Correspondence: n.l.butler@limu.ac.uk

${ }^{1}$ Public Health Institute, Liverpool John Moores University, 3rd Floor

Exchange Station, Tithebarn Street, Liverpool L2 2QP, UK

Full list of author information is available at the end of the article
}

\section{$\triangle B M C$}

C C The Author(s). 2020 Open Access This article is licensed under a Creative Commons Attribution 4.0 International License, which permits use, sharing, adaptation, distribution and reproduction in any medium or format, as long as you give appropriate credit to the original author(s) and the source, provide a link to the Creative Commons licence, and indicate if changes were made. The images or other third party material in this article are included in the article's Creative Commons licence, unless indicated otherwise in a credit line to the material. If material is not included in the article's Creative Commons licence and your intended use is not permitted by statutory regulation or exceeds the permitted use, you will need to obtain permission directly from the copyright holder. To view a copy of this licence, visit http://creativecommons.org/licenses/by/4.0/. The Creative Commons Public Domain Dedication waiver (http://creativecommons.org/publicdomain/zero/1.0/) applies to the data made available in this article, unless otherwise stated in a credit line to the data. 


\section{Background}

Interpersonal violence is a major public health issue, claiming over 1.3 million lives globally each year [1], and by 2030, homicide is expected to be amongst the top 20 causes of death [2]. Globally, the homicide rate for male populations is approximately four times higher than that for females; however, females comprise over four fifths of homicides carried out by intimate partners and bear the largest burden of victimisation in the context of intimate partner violence [3]. Non-fatal forms of violence are even more prevalent than homicide and have serious consequences for lifelong health and wellbeing [4]. Globally, 35\% of women have experienced either physical and/or sexual intimate partner violence or non-partner sexual violence in their lifetime [5]. Recent evidence estimating the health burden associated with intimate partner and sexual violence shows that women who experience either form of violence are approximately twice as likely to have alcohol use disorders and more than twice as likely to have depression, compared to women who have not experienced such violence [5]. Across many countries, males are at even greater risk of severe non-fatal injuries as a result of interpersonal violence outside the home, compared to females, with studies of English populations finding that males are significantly more likely to be admitted to hospital or present at an emergency department for an assaultrelated injury [6-8]. Addressing the physical and mental health consequences of interpersonal violence imposes substantial burdens and costs on health services [9]. The estimated cost of non-fatal interpersonal violence amongst adults (aged 16+ years) to the NHS and other health care providers in England and Wales was over $£ 1.8$ billion during the year 2015/2016 [10]. Other cost estimates show that the costs of violence to the NHS are equivalent to those of other public health issues, such as alcohol and tobacco [11]. Thus, interpersonal violence has high individual, economic, and health service costs and represents an important public health issue. An improved understanding of the associated risk factors is crucial to informing effective intervention strategies to prevent, reduce, and respond to interpersonal violence.

Using a lifecourse perspective, there is evidence to support the concept of revictimisation that individuals who experience victimisation in childhood are at increased risk for subsequent victimisation in later life [12, 13]. Historically, much research on outcomes associated with child abuse have examined the impacts of individual types of abuse in isolation, with a review of studies in 2001 finding that only a small minority of published work in the area included more than one form of abuse [14]. Early studies of violence revictimisation thus tended to focus on a specific type of child abuse and its relationship with a particular, often similar, form of victimisation in adulthood. For example, studies have found that child sexual abuse increased the likelihood of being raped in adulthood by between two- and elevenfold $[15,16]$, whilst exposure to domestic abuse as a child has been associated with being a victim of domestic abuse as an adult [17] and exposing their own children to parental conflict [18]. This body of research implied that types of abuse occur individually. However, more recent research has demonstrated that child abuse, and other types of adversity, typically co-occur [19-21] and consequently studies which attribute risk of revictimisation to one specific form of abuse may be misleading.

Over the past two decades, increasing attention has focused on the contribution of co-occurring adverse childhood experiences (ACEs; including physical, sexual, and emotional abuse as well as markers of household dysfunction such as domestic violence) to a host of poor outcomes in adulthood, including experiencing violence [20]. Crucially, a recent systematic review and metaanalyses examining ACEs and health during adulthood found that violence victimisation was amongst the outcomes most strongly associated with experiencing multiple types of ACEs, with pooled odds ratios indicating individuals with four or more ACEs were over seven times more likely to have been a victim of violence, compared to those reporting none [22]. Estimates from a national study of households in England showed that a history of exposure to ACEs could account for approximately half of all adults experiencing violence victimisation in the past year [19]. This equates annually to over one million individuals being assaulted at the national population level [19]. Thus, addressing abuse and adversity in childhood is an important public health issue which is likely to have a downstream effect on levels of violence victimisation amongst adults.

Crucially, these studies also demonstrate that childhood adversity operates in an additive manner whereby there is a positive relationship between exposure to higher numbers of ACEs and increased risk of a range of poor outcomes [19, 20, 22]. Findings from a national household survey in England demonstrated the graded relationship between the number of ACEs experienced and the risk of violence victimisation as an adult. Compared to those who had no history of ACEs, individuals with experience of one ACE were over one and a half times more likely to have been a victim of violence in the past year, increasing to over four times more likely for those with 2-3 ACEs, and over seven times more likely for those with four or more ACEs [19]. This doseresponse relationship between childhood adversity and experience of violence in adulthood has also been replicated in several studies across different countries [2326]. To date however, there are a limited number of 
studies which examine the relationship between childhood abuse and different forms of adult interpersonal violence. Findings from US studies of a health care population demonstrated a strong graded relationship between the number of ACEs experienced and risk of being a victim of intimate partner violence [27] and sexual violence in adulthood [28]. However, the generalisability of the findings is limited by the use of a nonrepresentative health care sample.

Studies to date have typically focused on the cumulative burden of ACEs or focused specifically on an individual ACE. The cumulative ACE approach has provided a means of synthesising complex evidence to demonstrate the impact of adversity on a wide range of public health outcomes, and, in some countries, this has been instrumental in affecting national policy changes $[29,30]$. Consistent findings across ACE studies, often despite differences in methodology, settings, and types of ACEs measured, suggest some consistency in the impact of ACEs in different populations [22]. However, it has also been highlighted that such aggregative approaches are best supplemented by complementary studies to investigate the potentially differential impact of different types, or combination of types, of adversity [20, 22, 31, 32]. One ACE study considered types of abuse in addition to the number of types on risk of sexual violence in adulthood [28]. Crucially, the study demonstrated that, whilst all ACE variables were significantly associated with sexual violence victimisation in adulthood, child sexual abuse was the strongest predictor of adult sexual violence. Furthermore, consistent with the ACE cumulative impact hypothesis, additional adversities experienced by child sexual abuse victims increased the risk of adulthood sexual violence, beyond the risk associated with child sexual abuse alone [28]. Findings from the study suggest both the type of abuse and the number of types are important. However, conclusions from the study were limited by the health care population sample and, crucially, the focus on one specific type of adulthood violence. There is evidence to suggest that different combinations of types may be associated with different outcomes in adulthood [33]. However, study of the specificity of abuse on different types of revictimisation has largely been neglected.

The primary aim of the current study is to examine the relationship between abuse in childhood and violence revictimisation in adulthood, including intimate partner violence, sexual violence and physical assault, using data from a nationally representative general population sample. Given that, to date, research has typically examined the impacts of childhood adversity either from an aggregative perspective, with less regard to type of adversity, or a type perspective, with less regard to multi-type victimisation, we include consideration of both type of childhood abuse and number of types in the current study.

\section{Methods}

\section{Data source}

Data for the current study was drawn from the 2015/ 2016 Crime Survey for England and Wales (CSEW) [34]. The CSEW is a face-to-face survey in which permanent residents of households in England and Wales are asked about their experiences of crime. It includes adults aged 16 and over except those living in institutions or group accommodation (e.g. halls of residence, care homes, homeless shelters). Face-to-face interviews are carried out using computer-assisted personal interviewing for the victimisation module, including all questions on interpersonal violence and household crime, and computer-assisted self-interviewing for self-completion modules on sensitive issues such as domestic abuse, sexual assault, and stalking [35]. The CSEW also occasionally includes modules of questions on topical issues, and the 2015/2016 CSEW incorporated, for the first time, a self-complete module of questions which asked adult respondents whether they experienced abuse as a child (before the age of 16 years).

The CSEW sample design and methods are discussed in detail elsewhere $[35,36]$. The CSEW uses a random probability approach stratified by police force area and then by lower super output areas (LSOAs; geographical areas with a population average of 1500 individuals [37]). The survey is weighted to adjust for possible nonresponse bias to ensure the sample reflects the profile of the general population. Thus, the core sample is designed to be representative of the population of households in England and Wales. The Postcode Address File is used as the address source for the CSEW, with postcodes and LSOAs linked via the Office for National Statistics' (ONS) National Statistics Postcode Lookup database, allowing addresses to be allocated to sample strata. Within each police force area, the number of addresses is based on the target number of interviews to be achieved across the year divided by the estimated address conversion rate. The number of addresses selected for the 2015/2016 CSEW varied within each sample unit but averaged 38 , with 54,074 addresses initially sampled, of which 48,991 were eligible (i.e. occupied). Within each eligible household, one adult was randomly selected for interview based on a standard selection algorithm. A total of 35,146 interviews were conducted, accounting for a final response rate of $71.7 \%$ [36]. The self-complete module of the survey, which includes domestic abuse, sexual assault, and child abuse, is restricted to adults aged 16-59 years due to considerations around data 
quality and respondent burden [38]. Thus, the total sample size in the current study was 21,845 .

\section{Measures \\ Childhood abuse}

Childhood abuse was assessed using questions from the self-completion module: experience of abuse during childhood. Child physical abuse (CPA) consisted of one item indicating that respondents were deliberately pushed, held down, or slapped hard; kicked, bitten, or hit with a fist or something else; had something thrown at them; were choked or had someone attempt to strangle them; hit or attacked with a weapon or an object; burned; or had some other kind of force inflicted against them in a non-sexual way. ${ }^{1}$ Child psychological abuse (CPsychA) was measured with one item where the respondent indicates that they were not loved, told that they should never have been born, threatened with abandonment or eviction from family home, repeatedly belittled, physically threatened, or emotionally neglected. Child sexual abuse (CSA) was measured using three items which included sexual assault by rape or penetration, including attempts, or other sexual assaults including indecent exposure or sexual touching. Children witnessing domestic violence $(\mathrm{CWDV})^{2}$ was measured using one item which asked if the respondent had witnessed domestic violence or abuse, including any psychological, physical, or sexual assault in the home, during childhood. All items pertained to abuse the respondent had experienced before the age of 16 years and which was perpetrated by an adult. The response categories were yes, no, do not know, and do not wish to answer. A count variable of the number of types of childhood abuse was created and categorised as none, single type, and multiple types.

\section{Adulthood violence victimisation}

Three types of adulthood violence victimisation were included in the current study: non-sexual intimate partner violence (IPV) since age 16 years, sexual violence (SV) since 16 years, and past year physical assault (PA). Nine items from the self-completion module: domestic violence, sexual victimisation, and stalking module, were combined to create one variable to indicate the presence of IPV (Additional file 1: Table A1). Eight items from the same module were combined to create one variable to indicate the presence of SV. Physical assault in the past 12 months was assessed using a derived variable (from the non-victim form CSEW 2015/2016 dataset),

\footnotetext{
${ }^{1}$ Includes smacking or corporal punishment at school, but excludes peer on peer bullying.

${ }^{2}$ Whilst we acknowledge children 'experience' domestic violence, we refer to 'witnessing' domestic violence to maintain consistency with the CSEW survey question.
}

produced by the Home Office/ONS, which combined all CSEW offence codes ${ }^{3}$ related to assault, including violence with and without injury, including both completed and attempted incidents. As questions used to create the derived variable for physical assault are asked of all survey participants, but questions on intimate partner violence and sexual violence are limited to adults aged 1659 years, the sample for the current study was limited to respondents aged $16-59$ years to ensure the same sample of individuals was used for each violence outcome.

\section{Covariates}

Demographic characteristics controlled for in logistic regressions included sex (male or female), age (years 16-59), ethnicity (white or others), and deprivation. Deprivation is measured in the CSEW using the English Index of Multiple Deprivation (IMD) 2015 [39] and Welsh IMD 2014 [40], which comprise of different domains, or measures, of deprivation including, for example, income, employment, health, and crime. Measuring deprivation in this way allows the inclusion of a wide range of aspects of an individual's living conditions [41]. The IMD is the official measure of relative deprivation for small geographies called lower super output areas (LSOAs; areas with mean population of 1500 [37]). LSOAs are categorised into deprivation quintiles ( 1 , most deprived; 5 , least deprived) based on their ranking in the IMD within their respective countries. Participants in the CSEW are then grouped based on the quintiles of IMD score in the country where they reside.

\section{Statistical analyses}

All analyses were undertaken using SPSS (v24). Similar to practice elsewhere, missing values for childhood abuse measures were coded as a negative response [19, 42]. This approach allows the inclusion of cases where a data point is missing in one variable and not in another, controlling for the effects of missing data [42]. Only individuals with complete data for the violence outcome of interest (i.e. intimate partner violence, sexual violence or physical assault), age, sex, and ethnicity were included in the logistic regression analysis. Where individuals did not answer all relevant questions, final sample sizes are presented. Logistic regression was used to examine the independent relationships between child abuse types, and number of types, and adult violence outcomes, after controlling for sociodemographics. To examine the relationship between childhood abuse and adulthood violence victimisation, three regression models were ran for

\footnotetext{
${ }^{3}$ Based on information collected from the victimisation modules, specially trained coders determine whether what is reported constitutes a crime, and if so, what offence code should be assigned to the crime.
} 
each violence outcome (each controlling for sociodemographics). Model 1 included child abuse count; model 2 included all individual types of child abuse; and model 3 included both child abuse count and all individual types of child abuse.

\section{Results}

Information about the demographic characteristics of individuals included in the current study is provided in Additional file 1: Table A2. 18.6\% $(n=4058)$ of adults aged 16-59 years reported at least one form of childhood abuse, with $10.6 \%(n=2316)$ reporting a single type of child abuse and $8.0 \%(n=1742)$ two or more types. Sample prevalence rates of individual types of childhood abuse are presented in Table 1. All child abuse types were significantly associated with each other, with the strongest association between CPsychA and CPA, and the weakest association between CSA and CWDV (Additional file 1: Table A3). Females were more likely than males to have experienced at least one type of child abuse and also more likely to report CPsychA, CSA, and CWDV (Table 1). There was also a significant association between each individual type of childhood abuse and age, and abuse count and age, with the youngest age group having the lowest prevalence across all CM categories (Table 1). White respondents were more likely to report all individual types of childhood abuse and multiple forms of abuse than individuals of other ethnicities (Table 1). The relationship between deprivation and prevalence of childhood abuse differed by type of abuse, with higher prevalence of CPsychA and CWDV amongst more deprived quintiles (1-3) compared to less deprived quintiles (4 and 5). The

Table 1 Bivariate relationships between sociodemographics and childhood abuse $(<16$ years)

\begin{tabular}{|c|c|c|c|c|c|c|c|c|}
\hline & & \multirow{2}{*}{$\begin{array}{l}\text { Childhood } \\
\text { psychological } \\
\text { abuse }\end{array}$} & \multirow{2}{*}{$\begin{array}{l}\text { Childhood } \\
\text { physical } \\
\text { abuse }\end{array}$} & \multirow{2}{*}{$\begin{array}{l}\text { Childhood } \\
\text { sexual } \\
\text { abuse }\end{array}$} & \multirow{2}{*}{$\begin{array}{l}\text { Childhood } \\
\text { witnessing } \\
\text { domestic } \\
\text { violence }\end{array}$} & \multicolumn{3}{|c|}{ Childhood abuse count } \\
\hline & & & & & & None & Single type & Multiple types \\
\hline All & $\%(N)$ & $9.0(1971)$ & $6.9(1512)$ & $6.9(1513)$ & $8.1(1777)$ & $81.4(17,787)$ & $10.6(2316)$ & $8.0(1742)$ \\
\hline \multicolumn{9}{|l|}{ Sex } \\
\hline Male & $\%(n)$ & $6.8(678)$ & $6.9(680)$ & $2.8(275)$ & $6.0(597)$ & $86.0(8517)$ & $8.4(829)$ & $5.7(563)$ \\
\hline Female & $\%(n)$ & $10.8(1293)$ & $7.0(832)$ & $10.4(1238)$ & $9.9(1180)$ & $77.7(9270)$ & $12.5(1487)$ & 9.9 (1179) \\
\hline$x^{2}$ & & 104.547 & 0.082 & 483.524 & 107.503 & 250.723 & & \\
\hline$p$ & & $<0.001$ & 0.774 & $<0.001$ & $<0.001$ & $<0.001$ & & \\
\hline \multicolumn{9}{|l|}{ Age (years) } \\
\hline $16-19$ & $\%(n)$ & $7.8(72)$ & $3.6(33)$ & $2.1(19)$ & $4.1(38)$ & $88.0(809)$ & $7.9(73)$ & $4.0(37)$ \\
\hline $20-29$ & $\%(n)$ & $9.8(381)$ & $6.5(254)$ & $4.8(187)$ & $8.9(345)$ & $82.5(3210)$ & $9.5(370)$ & $8.0(310)$ \\
\hline $30-39$ & $\%(n)$ & $8.4(450)$ & $7.0(374)$ & $5.7(304)$ & $8.1(437)$ & $82.4(4427)$ & $10.2(548)$ & $7.4(399)$ \\
\hline $40-49$ & $\%(n)$ & $9.8(587)$ & $7.4(439)$ & $8.2(492)$ & $8.9(532)$ & $79.9(4764)$ & $11.2(667)$ & $9.0(534)$ \\
\hline $50-59$ & $\%(n)$ & $8.4(481)$ & $7.2(412)$ & $9.0(511)$ & $7.5(425)$ & $80.3(4577)$ & $11.5(658)$ & $8.1(462)$ \\
\hline$x^{2}$ & & 14.355 & 19.393 & 127.254 & 30.856 & 54.025 & & \\
\hline$p$ & & $<0.01$ & $<0.01$ & $<0.001$ & $<0.001$ & $<0.001$ & & \\
\hline \multicolumn{9}{|l|}{ Deprivation quintile } \\
\hline 1 (most deprived) & $\%(n)$ & $9.6(433)$ & $7.2(322)$ & $6.4(287)$ & $8.4(379)$ & $82.2(3700)$ & $9.3(420)$ & $8.4(379)$ \\
\hline 2 & $\%(n)$ & $9.4(414)$ & $7.8(342)$ & $6.0(264)$ & $9.2(407)$ & $80.9(3562)$ & $10.3(454)$ & $8.8(386)$ \\
\hline 3 & $\%(n)$ & 9.7 (419) & $6.9(297)$ & $7.5(321)$ & $8.3(355)$ & $80.6(3466)$ & $11.0(473)$ & $8.4(361)$ \\
\hline 4 & $\%(n)$ & 8.7 (377) & $6.4(277)$ & $7.6(331)$ & 7.7 (336) & $81.3(3543)$ & $11.1(485)$ & $7.6(330)$ \\
\hline 5 (least deprived) & $\%(n)$ & 7.7 (328) & $6.4(274)$ & $7.2(310)$ & $7.0(300)$ & $82.0(3516)$ & $11.3(484)$ & $6.7(286)$ \\
\hline$x^{2}$ & & 16.027 & 9.320 & 13.569 & 16.304 & 27.499 & & \\
\hline$p$ & & $<0.01$ & 0.054 & $<0.01$ & $<0.01$ & $<0.01$ & & \\
\hline \multicolumn{9}{|l|}{ Ethnicity } \\
\hline White & $\%(n)$ & $9.5(1813)$ & $7.2(1380)$ & $7.3(1395)$ & $8.5(1613)$ & $80.4(15,317)$ & $11.2(2129)$ & $8.4(1598)$ \\
\hline Others & $\%(n)$ & $5.7(157)$ & $4.7(131)$ & $4.3(118)$ & $5.9(164)$ & $88.1(2436)$ & $6.8(187)$ & $5.2(143)$ \\
\hline$x^{2}$ & & 42.967 & 23.216 & 34.536 & 20.495 & 93.120 & & \\
\hline$p$ & & $<0.001$ & $<0.001$ & $<0.001$ & $<0.001$ & $<0.001$ & & \\
\hline
\end{tabular}


prevalence of CSA however was higher amongst less deprived quintiles (3-5) compared to more deprived quintiles (1 and 2). Childhood abuse count was also significantly associated with deprivation, with higher levels of deprivation (quintiles 1-3) associated with higher prevalence of multiple forms of childhood abuse (Table 1). Overall, differences between deprivation levels were relatively small, and abuse was prevalent across all quintiles of deprivation (Table 1).

\section{Intimate partner violence (IPV)}

Of the sample, $18.9 \%(n=3681)$ had experienced some form of intimate partner violence (IPV) since the age of 16. In bivariate analyses, all individual types of childhood abuse and the combined variable childhood abuse count were significantly associated with IPV (Additional file 1: Table A4). Each individual type of childhood abuse remained significantly associated with IPV, after controlling for sociodemographics (age, gender, ethnicity, and deprivation), with adjusted odds ratios (AORs) ranging from 3.21 (CSA) to 5.09 (CPsychA) (Additional file 1: Table A4). After controlling for sociodemographics, child abuse count indicated a graded relationship with IPV, with the AOR for experiencing multiple types of abuse approximately twice as high as the AOR for a single form of abuse (Table 2; model 1). When all individual types of childhood abuse were entered simultaneously into the model, relationships with IPV were attenuated (compared to unadjusted measures) but all individual types remained independently associated with increased odds of IPV (Table 2; model 2). When childhood abuse count was added into the model along with all individual types, abuse count and CPsychA and CPA independently predicted IPV (Table 2; model 3).

\section{Sexual violence (SV)}

Of the sample, $13.0 \%(n=2623)$ had experienced sexual violence (SV) since age 16. In unadjusted analyses, all individual types of childhood abuse and childhood abuse count were significantly associated with SV (Additional file 1: Table A4). After controlling for sociodemographics (age, gender, ethnicity, and deprivation), each individual type of childhood abuse remained significantly associated with SV, with AORs ranging from 3.40

Table 2 Associations between childhood abuse ( $<16$ years) and lifetime intimate partner violence victimisation $(\geq 16$ years) $(N=$ 19,471)

\begin{tabular}{|c|c|c|c|c|c|c|c|c|c|c|c|c|c|}
\hline & & \multicolumn{4}{|l|}{ Model 1} & \multicolumn{4}{|l|}{ Model 2} & \multicolumn{4}{|l|}{ Model 3} \\
\hline & & \multirow[t]{2}{*}{ Sig. } & \multirow[t]{2}{*}{ AOR } & \multicolumn{2}{|c|}{$95 \% \mathrm{Cls}$} & \multirow[t]{2}{*}{ Sig. } & \multirow[t]{2}{*}{ AOR } & \multicolumn{2}{|c|}{$95 \% \mathrm{Cls}$} & \multirow[t]{2}{*}{ Sig. } & \multirow[t]{2}{*}{ AOR } & \multicolumn{2}{|c|}{$95 \% \mathrm{Cls}$} \\
\hline & & & & $\overline{\mathrm{LL}}$ & UL & & & $\overline{\mathrm{LL}}$ & UL & & & $\overline{\mathrm{LL}}$ & UL \\
\hline \multicolumn{2}{|c|}{ Childhood psychological abuse } & - & & & & $<0.001$ & 2.78 & 2.45 & 3.15 & $<0.001$ & 1.56 & 1.33 & 1.82 \\
\hline \multicolumn{2}{|l|}{ Childhood physical abuse } & - & & & & $<0.001$ & 1.79 & 1.55 & 2.07 & $<0.05$ & 1.21 & 1.03 & 1.42 \\
\hline \multicolumn{2}{|l|}{ Childhood sexual abuse } & - & & & & $<0.001$ & 2.06 & 1.83 & 2.33 & NS & & & \\
\hline \multicolumn{2}{|c|}{ Childhood witnessing domestic violence } & - & & & & $<0.001$ & 1.76 & 1.55 & 2.00 & NS & & & \\
\hline \multirow[t]{3}{*}{ Childhood abuse count } & None (ref.) & $<0.001$ & & & & - & & & & $<0.001$ & & & \\
\hline & Single type & $<0.001$ & 3.27 & 2.95 & 3.62 & - & & & & $<0.001$ & 2.85 & 2.54 & 3.19 \\
\hline & Multiple types & $<0.001$ & 6.41 & 5.75 & 7.15 & - & & & & $<0.001$ & 3.96 & 3.22 & 4.87 \\
\hline Sex & Female & $<0.001$ & 2.52 & 2.32 & 2.74 & $<0.001$ & 2.53 & 2.33 & 2.76 & $<0.001$ & 2.57 & 2.36 & 2.79 \\
\hline \multirow[t]{5}{*}{ Age } & 50-59 (ref.) & & & & & $<0.001$ & & & & $<0.001$ & & & \\
\hline & $16-19$ & $<0.01$ & 0.65 & 0.49 & 0.85 & $<0.05$ & 0.64 & 0.48 & 0.83 & $<0.01$ & 0.62 & 0.48 & 0.82 \\
\hline & $20-29$ & NS & 0.97 & 0.86 & 1.10 & NS & 0.96 & 0.85 & 1.08 & NS & 0.96 & 0.85 & 1.09 \\
\hline & $30-39$ & $<0.05$ & 1.14 & 1.02 & 1.27 & $<0.05$ & 1.13 & 1.02 & 1.26 & $<0.05$ & 1.13 & 1.02 & 1.26 \\
\hline & $40-49$ & $<0.001$ & 1.25 & 1.13 & 1.39 & $<0.001$ & 1.24 & 1.12 & 1.37 & $<0.001$ & 1.25 & 1.12 & 1.38 \\
\hline Ethnicity & White & $<0.001$ & 1.91 & 1.65 & 2.21 & $<0.001$ & 1.97 & 1.70 & 2.28 & $<0.001$ & 1.91 & 1.65 & 2.21 \\
\hline \multirow[t]{5}{*}{ Deprivation } & Least deprived (ref.) & & & & & $<0.001$ & & & & $<0.001$ & & & \\
\hline & Most deprived-1 & $<0.001$ & 1.43 & 1.26 & 1.62 & $<0.001$ & 1.40 & 1.23 & 1.58 & $<0.001$ & 1.42 & 1.25 & 1.61 \\
\hline & 2 & $<0.001$ & 1.40 & 1.23 & 1.58 & $<0.001$ & 1.40 & 1.24 & 1.58 & $<0.001$ & 1.39 & 1.23 & 1.58 \\
\hline & 3 & $<0.001$ & 1.26 & 1.12 & 1.43 & $<0.001$ & 1.25 & 1.11 & 1.42 & $<0.001$ & 1.26 & 1.11 & 1.42 \\
\hline & 4 & NS & 1.11 & 0.98 & 1.25 & NS & 1.10 & 0.97 & 1.25 & NS & 1.11 & 0.98 & 1.25 \\
\hline
\end{tabular}

Notes. Limited to adults aged 16-59 years who completed the CSEW 2015/2016 self-completion modules. AOR adjusted odds ratio, $95 \%$ Cls $95 \%$ confidence intervals, LL lower limit, UL upper limit

Model 1: Childhood abuse count was entered in a regression, controlling for sociodemographics (sex, age, ethnicity, and deprivation quintiles) Model 2: All childhood abuse types were entered in a regression, controlling for sociodemographics

Model 3: All childhood abuse types and childhood abuse count were entered into a regression, controlling for sociodemographics 
(CWDV) to 5.80 (CSA) (Additional file 1: Table A4). Childhood abuse count also remained significantly associated with SV, after controlling for sociodemographics and indicated a graded relationship (Table 3; model 1). When all individual types of childhood abuse were entered simultaneously into the same model, relationships were weakened but remained significantly associated with increased odds of SV (Table 3; model 2). When childhood abuse count was added into the model along with all individual types, abuse count and CPsychA and CSA independently predicted SV (Table 3; model 3).

\section{Physical assault (PA)}

Of the sample, $2.4 \%(n=531)$ had experienced a physical assault (PA) in the past 12 months. In unadjusted analyses, all individual types of childhood abuse and childhood abuse count were significantly associated with PA (Additional file 1: Table A4). After controlling for sociodemographics (age, gender, ethnicity, and deprivation), each individual type of childhood abuse remained significantly associated with $\mathrm{PA}$, with AORs ranging from 2.41 (CSA) to 3.14 (CPsychA) (Additional file 1: Table A4). Childhood abuse count also remained significantly associated with PA and indicated a graded relationship (Table 4; model 1). When all types of childhood abuse were entered simultaneously into the same model, CPA was no longer significantly associated with PA. Relationships between CPsychA, CSA, and CWDV, and PA were attenuated but remained statistically significant (Table 4; model 2). When childhood abuse count was added into the model along with all individual types, abuse count and CPsychA independently predicted PA (Table 4; model 3).

\section{Discussion}

Using data from a nationally representative sample of adults resident in England and Wales, findings from the study demonstrated strong associations between childhood abuse and three types of violence revictimisation in adulthood: past year physical assault (PA), and intimate partner violence (IPV) and sexual violence victimisation (SV) since age 16 years. Consistent with early approaches in the field of child abuse research [15-18], examining types of abuse individually in the current study demonstrated that all types were significantly associated with each adult violence outcome, after

Table 3 Associations between childhood abuse (<16years) and lifetime sexual violence victimisation $(\geq 16$ years) $(N=20,129)$

\begin{tabular}{|c|c|c|c|c|c|c|c|c|c|c|c|c|c|}
\hline & & \multicolumn{4}{|c|}{ Model 1} & \multicolumn{4}{|l|}{ Model 2} & \multicolumn{4}{|c|}{ Model 3} \\
\hline & & \multirow[t]{2}{*}{ Sig. } & \multirow[t]{2}{*}{ AOR } & \multicolumn{2}{|c|}{$95 \% \mathrm{Cls}$} & \multirow[t]{2}{*}{ Sig. } & \multirow[t]{2}{*}{ AOR } & \multicolumn{2}{|c|}{$95 \% \mathrm{Cls}$} & \multirow[t]{2}{*}{ Sig. } & \multirow[t]{2}{*}{ AOR } & \multicolumn{2}{|c|}{$95 \% \mathrm{Cls}$} \\
\hline & & & & $\overline{\mathrm{LL}}$ & UL & & & $\overline{\mathrm{LL}}$ & UL & & & $\overline{\mathrm{LL}}$ & UL \\
\hline \multicolumn{2}{|c|}{ Childhood psychological abuse } & - & & & & $<0.001$ & 2.53 & 2.19 & 2.92 & $<0.001$ & 1.63 & 1.34 & 1.98 \\
\hline \multicolumn{2}{|l|}{ Childhood physical abuse } & - & & & & $<0.001$ & 1.50 & 1.27 & 1.78 & NS & & & \\
\hline \multicolumn{2}{|l|}{ Childhood sexual abuse } & - & & & & $<0.001$ & 4.20 & 3.71 & 4.75 & $<0.001$ & 2.47 & 2.10 & 2.91 \\
\hline \multicolumn{2}{|c|}{ Childhood witnessing domestic violence } & - & & & & $<0.001$ & 1.46 & 1.26 & 1.69 & NS & & & \\
\hline \multirow[t]{3}{*}{ Childhood abuse count } & None (ref.) & $<0.001$ & & & & - & & & & $<0.001$ & & & \\
\hline & Single type & $<0.001$ & 3.58 & 3.195 & 4.01 & - & & & & $<0.001$ & 2.16 & 1.85 & 2.52 \\
\hline & Multiple types & $<0.001$ & 6.89 & 6.11 & 7.76 & - & & & & $<0.001$ & 3.06 & 2.42 & 3.86 \\
\hline Sex & Female & $<0.001$ & 6.77 & 5.99 & 7.66 & $<0.001$ & 6.36 & 5.62 & 7.21 & $<0.001$ & 6.29 & 5.56 & 7.12 \\
\hline \multirow[t]{5}{*}{ Age } & 50-59 (ref.) & NS & & & & NS & & & & NS & & & \\
\hline & $16-19$ & & & & & & & & & & & & \\
\hline & $20-29$ & & & & & & & & & & & & \\
\hline & $30-39$ & & & & & & & & & & & & \\
\hline & $40-49$ & & & & & & & & & & & & \\
\hline Ethnicity & White & $<0.001$ & 1.51 & 1.28 & 1.78 & $<0.001$ & 1.55 & 1.32 & 1.84 & $<0.001$ & 1.52 & 1.28 & 1.79 \\
\hline \multirow[t]{5}{*}{ Deprivation } & Least deprived (ref.) & $<0.001$ & & & & $<0.001$ & & & & $<0.001$ & & & \\
\hline & Most deprived-1 & $<0.001$ & 0.72 & 0.62 & 0.83 & $<0.001$ & 0.71 & 0.61 & 0.82 & $<0.001$ & 0.72 & 0.62 & 0.84 \\
\hline & 2 & NS & 0.88 & 0.76 & 1.01 & NS & 0.91 & 0.79 & 1.05 & NS & 0.91 & 0.79 & 1.05 \\
\hline & 3 & NS & 0.97 & 0.85 & 1.12 & NS & 0.98 & 0.85 & 1.12 & NS & 0.98 & 0.85 & 1.12 \\
\hline & 4 & NS & 1.14 & 0.99 & 1.30 & NS & 1.14 & 0.99 & 1.30 & NS & 1.14 & 0.99 & 1.31 \\
\hline
\end{tabular}

Notes. Limited to adults aged 16-59 years who completed the CSEW 2015/2016 self-completion modules. AOR adjusted odds ratio, 95\% Cls 95\% confidence intervals, $L L$ lower limit, UL upper limit

Model 1: Childhood abuse count was entered in a regression, controlling for sociodemographics (sex, age, ethnicity, and deprivation quintiles)

Model 2: All childhood abuse types were entered in a regression, controlling for sociodemographics

Model 3: All childhood abuse types and childhood abuse count were entered in a regression, controlling for sociodemographics 
Table 4 Associations between childhood abuse (<16 years) and past year physical assault victimisation $(\geq 16$ years) $(N=21,810)$

\begin{tabular}{|c|c|c|c|c|c|c|c|c|c|c|c|c|c|}
\hline & & \multicolumn{4}{|c|}{ Model 1} & \multicolumn{4}{|c|}{ Model 2} & \multicolumn{4}{|c|}{ Model 3} \\
\hline & & \multirow[t]{2}{*}{ Sig. } & \multirow[t]{2}{*}{ AOR } & \multicolumn{2}{|c|}{$95 \% \mathrm{Cls}$} & \multirow[t]{2}{*}{ Sig. } & \multirow[t]{2}{*}{ AOR } & \multicolumn{2}{|c|}{$95 \% \mathrm{Cls}$} & \multirow[t]{2}{*}{ Sig. } & \multirow[t]{2}{*}{ AOR } & \multicolumn{2}{|c|}{$95 \% \mathrm{Cls}$} \\
\hline & & & & $\mathrm{LL}$ & UL & & & $\mathrm{LL}$ & UL & & & LL & UL \\
\hline \multicolumn{2}{|c|}{ Childhood psychological abuse } & - & & & & $<0.001$ & 2.37 & 1.84 & 3.06 & $<0.01$ & 1.61 & 1.13 & 2.31 \\
\hline \multicolumn{2}{|l|}{ Childhood physical abuse } & - & & & & NS & & & & NS & & & \\
\hline \multicolumn{2}{|l|}{ Childhood sexual abuse } & - & & & & $<0.01$ & 1.61 & 1.21 & 2.14 & NS & & & \\
\hline \multicolumn{2}{|c|}{ Childhood witnessing domestic violence } & - & & & & $<0.01$ & 1.50 & 1.14 & 1.98 & NS & & & \\
\hline \multirow[t]{3}{*}{ Childhood abuse count } & None (ref.) & $<0.001$ & & & & - & & & & $<0.001$ & & & \\
\hline & Single type & $<0.001$ & 2.16 & 1.70 & 2.75 & - & & & & $<0.001$ & 1.86 & 1.42 & 2.45 \\
\hline & Multiple types & $<0.001$ & 3.37 & 2.68 & 4.24 & - & & & & $<0.001$ & 2.25 & 1.53 & 3.32 \\
\hline Sex & Female & $<0.001$ & 0.68 & 0.57 & 0.81 & $<0.001$ & 0.67 & 0.56 & 0.80 & $<0.001$ & 0.69 & 0.58 & 0.82 \\
\hline \multirow[t]{5}{*}{ Age } & 50-59 (ref.) & $<0.001$ & & & & $<0.001$ & & & & $<0.001$ & & & \\
\hline & $16-19$ & $<0.001$ & 2.13 & 1.40 & 3.27 & $<0.01$ & 2.08 & 1.36 & 3.19 & $<0.01$ & 2.07 & 1.35 & 3.17 \\
\hline & $20-29$ & $<0.001$ & 2.20 & 1.68 & 2.88 & $<0.001$ & 2.16 & 1.65 & 2.83 & $<0.001$ & 2.17 & 1.66 & 2.83 \\
\hline & $30-39$ & $<0.01$ & 1.55 & 1.19 & 2.03 & $<0.01$ & 1.55 & 1.18 & 2.03 & $<0.01$ & 1.54 & 1.18 & 2.02 \\
\hline & $40-49$ & $<0.05$ & 1.37 & 1.05 & 1.80 & $<0.05$ & 1.35 & 1.03 & 1.76 & $<0.05$ & 1.36 & 1.04 & 1.78 \\
\hline Ethnicity & White & $<0.01$ & 1.72 & 1.26 & 2.36 & $<0.001$ & 1.75 & 1.28 & 2.39 & $<0.01$ & 1.72 & 1.26 & 2.35 \\
\hline \multirow[t]{5}{*}{ Deprivation } & Least deprived (ref.) & $<0.001$ & & & & $<0.001$ & & & & $<0.001$ & & & \\
\hline & Most deprived-1 & $<0.001$ & 1.92 & 1.44 & 2.55 & $<0.001$ & 1.88 & 1.41 & 2.50 & $<0.001$ & 1.91 & 1.43 & 2.54 \\
\hline & 2 & $<0.01$ & 1.52 & 1.13 & 2.04 & $<0.01$ & 1.52 & 1.13 & 2.05 & $<0.01$ & 1.52 & 1.13 & 2.04 \\
\hline & 3 & NS & 1.13 & 0.82 & 1.54 & NS & 1.117 & 0.82 & 1.53 & NS & 1.12 & 0.82 & 1.54 \\
\hline & 4 & NS & 1.26 & 0.93 & 1.71 & NS & 1.251 & 0.92 & 1.70 & NS & 1.26 & 0.93 & 1.71 \\
\hline
\end{tabular}

Notes. Limited to adults aged 16-59 years who completed the CSEW 2015/2016 self-completion modules. AOR adjusted odds ratio, 95\% Cls $95 \%$ confidence intervals, $L L$ lower limit, UL upper limit

Model 1: Childhood abuse count was entered in a regression, controlling for sociodemographics (sex, age, ethnicity, and deprivation quintiles)

Model 2: All childhood abuse types were entered in a regression, controlling for sociodemographics

Model 3: All childhood abuse types and childhood abuse count were entered in a regression, controlling for sociodemographics

controlling for sociodemographics. Crucially, and consistent with more recent research [19], our findings also showed correlation and co-occurrence of abuse types, providing further evidence that multiple types of abuse should be considered together in both research and practice. Thus, studies which examine a single form of abuse could erroneously attribute the increased risk of revictimisation as the unique impact of the type of abuse under study. When all individual types of abuse were considered together in the current study, most relationships with adult violence outcomes were attenuated but remained significant, suggesting child abuse in general, regardless of type, increases the risk of PA, IPV, and SV in adulthood. Further, consistent with findings elsewhere $[19,22,23,26-28]$, the current study demonstrated a cumulative impact of child abuse on risk of violence revictimisation. Compared to individuals who experienced no abuse in childhood, those who experienced one form of abuse were over twice as likely to report PA in the past year and three times as likely to have experienced IPV and/or SV since age 16 years. Crucially, individuals who experienced multiple types were three, six, and seven times more likely than those who experienced no abuse to have experienced PA, IPV, and SV, respectively. Thus, whilst most abuse types were independently related to past year PA and IPV and SV since age 16 years, the strongest predictor of each adulthood violence outcome was experiencing multiple forms of abuse in childhood.

Whilst child abuse in general, regardless of type, was associated with increased risk of revictimisation particularly for individuals who had experienced multiple types, the current study expanded previous research on revictimisation by demonstrating that when the effects of experiencing multiple forms of abuse were accounted for, type of abuse remained predictive of adult violence outcomes. Such findings are consistent with previous research showing that specific types of adversity account for impairment in areas such as mental health above the cumulative impact of number of types of abuse [43, 44]. This suggests that the effects of particular combinations of childhood abuse may be obscured when each type is given an equal weight, as in the aggregative count approach. Crucially, the type or combination of types which increased risk differed by violence outcome in the current study. After accounting for sociodemographics and multi-type 
victimisation, $\mathrm{CPsych} A$ and $\mathrm{CPA}$ remained significantly associated with IPV; CPsychA and CSA remained associated with SV; and CPsychA was the only childhood abuse type which remained associated with PA. That differential combinations of abuse are associated with different violence outcomes is in line with previous studies that consider both type and number of types, and which found specificity of types of abuse on mental illness outcomes in child and adult samples [33, 45].

Childhood abuse is not a direct causal factor of violence victimisation in adulthood but rather abuse is likely to disrupt normative developmental processes, such as secure attachment to the caregiver which enables children to regulate behaviour and emotions [46, 47], create difficulties relating to others and forming healthy relationships [48-50], and cause problems in areas such as aggression, hyper arousal, and impulse control [51-53]. These factors may function as adaptive reactions in abusive environments, but conversely may also increase risk of revictimisation. For example, experiencing hyper arousal on a consistent basis may increase vigilance to danger cues in the environment but equally reduce the ability to differentiate serious threat cues from less serious, increasing risk of revictimisation [54]. Aggression and problems with impulse control are associated with increased likelihood to associate with delinquent peers and involvement in violence [55-57], whilst some research suggests experiencing or witnessing violent behaviour as a child might lead to learned expectations that the use of violence to resolve conflicts in relationships is normative or that complying with a violent partner is a means of reducing further harm [58, 59]. Some studies suggest that pathways may differ by adulthood violence outcome, with evidence that the association between CSA and SV is mediated via problematic alcohol use and risky sexual behaviour including early onset sexual activity, multiple sexual partners, and promiscuous sexual behaviour [60,61], whilst the association between childhood adversity and IPV has been found to be mediated by psychosocial characteristics including depression, anxiety, and impulsivity [62]. Although further research is required, such pathways and mediating processes between child abuse and adulthood revictimisation may represent important targets for public health interventions [63]. However, universal and selective interventions which promote positive parentchild relationships and supportive relationships from other appropriate adults have the potential to prevent and/or mitigate the impact of childhood abuse [64] and are likely to be the most effective at the population level in reducing multiple forms of revictimisation in adulthood. The health sector plays a key role in implementing such intervention strategies, with the Safe Environment for Every Kid (SEEK) model in paediatric primary care and the Nurse-Family Partnership home visitation programme, examples of two programmes implemented in health care settings or by health care personnel, which are effective in reducing child abuse and domestic violence and improving child and parental health outcomes [65-67]. Findings from our study suggest such programmes may also indirectly reduce risk of violence victimisation across the lifecourse, thereby reducing the burden and cost associated with adulthood violence victimisation to health care systems.

That child abuse is associated with repeat victimisation in adulthood also has important implications for adult health service provision as, similar to the additive manner in which child abuse impacts health and wellbeing, revictimisation in adulthood can further compound and exacerbate the effects of child abuse [68,69]. Further, the burden of interpersonal violence is disproportionately borne by small numbers of adults who experience high frequencies of victimisation, particularly in the case of IPV [70-72]. Thus, whilst not accounted for in the current study, such individuals are likely to be repeated victims of violence of one or more types in adulthood, further compounding trauma. Individuals who experience both child abuse and violence as an adult are at increased risk of trauma-associated health issues including mental health problems [73-75], substance use disorders [76], and adverse pregnancy outcomes [77]. Critically, many of the health impacts associated with interpersonal violence also represent adversities for the next generation, perpetuating the intergenerational transmission of adversity. Multi-sector efforts are increasingly underway to develop trauma-informed services, which recognise the relationship between current health and social problems and previous experience of trauma [78, 79]. Health sector services, such as substance misuse services, sexual health clinics, and mental health services, are likely to encounter higher proportions of individuals presenting with chronic adversity in their childhood histories compared to the general population [42, 80], and by adopting a trauma-informed approach to treatment, can better understand and address patient issues [81, 82]. Thus, the health sector can play a crucial role in interrupting the cycle of violence between childhood and adulthood victimisation, through both primary prevention of child abuse and trauma-informed approaches to addressing subsequent health and social outcomes and concurrently prevent or reduce levels of adversity in successive generations. Such efforts represent a lifecourse approach towards violence prevention and a focus on the early drivers of poor health and social outcomes. The UN 2030 Agenda for Sustainable Development Goals (SDGs) provides the political endorsement and multi-sectoral framework for such an approach, and whilst several of the SDGs directly concern violence, the 
achievement of other SDGs (e.g. good health and wellbeing, reduced inequalities) is also dependent on efforts across all sectors to address violence and its risk factors $[83,84]$.

\section{Limitations}

In light of the findings, several limitations of the study should also be considered. As with many population surveys, the CSEW is cross-sectional in design; thus, causality in the current study cannot be established. However, the temporal ordering of child abuse predictors and adult violence outcomes suggests child abuse increases risk of revictimisation. The use of 16 years by the CSEW as the cut-off between childhood and adulthood may mean that under other definitions of childhood abuse (i.e. before 18 years) some experiences of revictimisation in adulthood in the current study would be considered other incidences of child abuse. Further, questions on child abuse in the CSEW are not from a standardised instrument for measuring child abuse, although they are similar in format and content to questions used in adverse childhood experiences literature [19, 20]. Here we aimed to examine the strength of associations between exposure to child abuse and subsequent experiences in adulthood of physical and sexual assault. For those purposes, the use of logistic regression techniques is consistent with studies elsewhere $[19,20]$. Further analyses using statistical mediation techniques could allow additional understanding of the links between child abuse and adult outcomes in future studies. Data on behavioural and individual-level (beyond sociodemographics) factors, which may be potential mechanisms for the association between child abuse and risk of revictimisation, were unavailable in the CSEW data set to consider for inclusion in the analyses. Behavioural factors, such as perpetration of violence, delinquency, and substance use, and individual-level factors, such as self-regulation and psychopathology, have previously been demonstrated to be associated to child abuse and/or adulthood violence victimisation [85-87]; thus, investigation of the mechanisms through which revictimisation occurs is an important area for future research. The retrospective nature of the survey necessitates participants recalling abuse in childhood. Studies have shown complex trauma in childhood can be associated with repression of memory and dissociation, thus potentially increasing risk of underreporting of abuse [88]. The CSEW is a population household survey, thus excludes higher risk populations such as patients in psychiatric facilities, prisoners, or individuals experiencing homelessness where rates of child abuse and adulthood violence victimisation are higher than the general population [89-91]. Markers of household dysfunction have been demonstrated in other studies to further increase the cumulative risk of adverse outcomes, including experiencing violence, associated with childhood abuse [28]. No information was available on other types of adversity; however, child abuse has been previously found to be one of the strongest predictor of adverse outcomes [28, 42, 92]. The 2015/2016 CSEW did not however include all forms of child abuse, and although emotional neglect is covered within the definition of psychological abuse, physical neglect in childhood is omitted. Further, there was insufficient information on other factors which have been demonstrated to impact later outcomes including age of onset, severity, and chronicity of abuse to allow inclusion in the current study $[90,93]$.

\section{Conclusions}

Interpersonal violence, including both childhood and adulthood victimisation, is one of the most preventable causes of premature morbidity and mortality and represents key targets of the United Nation's Sustainable Development Goals [83]. Whilst prevention of all forms of child abuse is an important goal for ethical, health, and economic reasons, evidence from the current study suggests such prevention efforts will also have a downstream effect on preventing interpersonal violence across the lifecourse, disrupting cycles of victimisation. Results here demonstrate that experiencing multiple types of abuse is the strongest risk factor for violence revictimisation and suggest that individual types of abuse may be differentially associated with different violence outcomes in adulthood when multi-type victimisation is accounted for. This suggests potentially different pathways between childhood abuse and different types of adulthood interpersonal violence, which may have important implications for intervention efforts targeted at mediating factors. With adulthood victimisation likely to compound the already detrimental effects of childhood abuse $[68,69]$, there is a compelling case for focusing global public health and health sector efforts on preventing and mitigating the impacts of childhood abuse. Such efforts will not only reduce risk of revictimisation across the lifecourse for individuals, but given that exposure to such violence also represents adversities for the next generation, it represents a crucial means of disrupting intergenerational cycles of violence.

\section{Supplementary information}

Supplementary information accompanies this paper at https://doi.org/10. 1186/s12916-020-01788-3.

\footnotetext{
Additional file 1: Table A1. Adulthood violence victimisation items. Table A2. Respondent sociodemographics. Table A3. Changes in odds of reporting any type of childhood abuse with experiencing any other childhood abuse. Table A4. Bivariate and adjusted associations between child abuse ( $<16$ years) and adult violence victimisation ( $\geq 16$ years), CSEW $15 / 16$ adults aged $16-59$ years.
} 


\section{Abbreviations}

AORs: Adjusted odds ratios; ACEs: Adverse childhood experiences; CPA: Childhood physical abuse; CPsychA: Childhood psychological abuse; CSA: Childhood sexual abuse; CWDV: Childhood witnessing domestic violence; IMD: Index of Multiple Deprivation; IPV: Intimate partner violence; LSOAs: Lower super output areas; ONS: Office for National Statistics; PA: Physical assault; SV: Sexual violence

\section{Acknowledgements}

We thank the UK Data Service for their support accessing the data, Dr. Jude Towers for reviewing a draft manuscript, and all participants who took the time to take part in the Crime Survey for England and Wales.

\section{Authors' contributions}

NB designed the study, analysed the data, and wrote the manuscript. ZQ contributed to the study design, data analysis, and manuscript editing. MAB advised on the data analysis and edited the manuscript. The authors read and approved the final manuscript.

\section{Funding}

Support for the preparation of the manuscript was provided by Liverpool John Moores University and Public Health Wales.

\section{Availability of data and materials}

The data that support the findings of this study are available from UK Data Service but restrictions apply to the availability of these data, which were used under licence for the current study, and so are not publicly available. Data are however available from the UK Data Service and with permission of the Office for National Statistics.

\section{Ethics approval and consent to participate}

Ethical approval to access the data was obtained from Liverpool John Moores University and the study adhered to the Declaration of Helsinki. As part of the informed consent participants give to take part in the Crime Survey for England and Wales, they consent for their data to be used by the Office for National Statistics and other government departments, or approved organisations and approved researchers for statistical purposes (the current study falls under the latter).

\section{Consent for publication}

Not applicable

\section{Competing interests}

The authors declare that they have no competing interests.

\section{Author details}

${ }^{1}$ Public Health Institute, Liverpool John Moores University, 3rd Floor Exchange Station, Tithebarn Street, Liverpool L2 2QP, UK. ${ }^{2}$ College of Health and Behavioural Sciences, Bangor University, Bangor, UK. ${ }^{3}$ Policy and International Health Directorate, Public Health Wales, Clwydian House, Wrexham, UK.

\section{Received: 8 April 2020 Accepted: 17 September 2020}

\section{Published online: 16 November 2020}

\section{References}

1. World Health Organization. Global status report on violence prevention 2014. Geneva: World Health Organization; 2014.

2. World Health Organization. Injuries and violence: the facts. Geneva: World Health Organization; 2010.

3. UNODC. Global study on homicide. Vienna: United Nations Office on Drugs and Crime; 2019

4. World Health Organization. World report on violence and health. Geneva: World Health Organization; 2002.

5. World Health Organization. Global and regional estimates of violence against women: prevalence and health effects of intimate partner violence and non-partner sexual violence. Geneva: World Health Organization; 2013.

6. Bellis MA, Hughes K, Anderson Z, Tocque K, Hughes S. Contribution of violence to health inequalities in England: demographics and trends in emergency hospital admissions for assault. J Epidemiol Community Health. 2008;62:1064-71.
7. Bellis MA, Leckenby N, Hughes K, Luke C, Wyke S, Quigg Z. Nighttime assaults: using a national emergency department monitoring system to predict occurrence, target prevention and plan services. BMC Public Health. 2012;12(746):1-13.

8. Quigg Z, Hughes K, Bellis MA. Data sharing for prevention: a case study in the development of a comprehensive emergency department injury surveillance system and its use in preventing violence and alcohol-related harms. Injury Prevention. 2011;18(5):315-20.

9. Butchart A, Brown D, Khanh-Huynh A, Corso P, Florquin N, Muggah R. Manual for estimating the economic costs of injuries due to interpersonal and self-directed violence. Geneva: World Health Organization; 2008.

10. Heeks M, Reed S, Tafsiri M, Prince S. The economic and social costs of crime: second edition. London: Home Office; 2018.

11. Bellis MA, Huhhes K, Perkins C, Bennett A. Protecting people, promoting health: a public health approach to violence prevention for England. Liverpool: Centre for Public Health; 2012.

12. Widom CS, Czaja SJ, Dutton MA. Childhood victimization and lifetime revictimization. Child Abuse Negl. 2008;32(8):785-96.

13. Finkelhor D, Ormrod RK, Turner HA. Re-victimization patterns in a national longitudinal sample of children and youth. Chile Abuse Neglect. 2007;31(5): 479-502.

14. Higgins DJ, McCabe MP. Multiple forms of child abuse and neglect: adult retrospective reports. Aggress Violent Behav. 2001;6:547-78.

15. Fergusson DM, Horwood LJ, Lynskey MT. Childhood sexual abuse, adolescent sexual behaviors and sexual revictimization. Child Abuse Negl. 1997;21(8):789-802.

16. Arata CM. Child sexual abuse and sexual revictimization. Clin Psychol Sci Pract. 2002;9(2):135-64.

17. Coker AL, Hall Smith P, McKeown RE, King MJ. Frequency and correlates of intimate partner violence by type: physical, sexual, and psychological battering. Am J Public Health. 2000;90:553-9.

18. Cannon EA, Bonomi AE, Anderson ML, Rivara FP. The intergenerational transmission of witnessing intimate partner violence. Arch Pediatr Adolesc Med. 2009;163(8):706-8.

19. Bellis MA, Hughes K, Leckenby N, Perkins C, Lowey H. "National household survey of adverse childhood experiences and their relationship with resilience to health-harming behaviours in England," BMC Medicine. 2014; 12(72):1-10.

20. Felitti VJ, Anda RF, Nordenberg D, Williamson DF, Spitz AM, Edwards V, et al. Relationship of childhood abuse and household dysfunction to many of the leading causes of death in adults. Am J Preventative Med. 1998:245-58.

21. Herrenkohl RC, Herrenkohl T7. Assessing a child's experience of multiple maltreatment types: some unfinished business. J Family Violence. 2009;24(7):485.

22. Hughes $K$, Bellis MA, Hardcastle KA, Sethi D, Butchart A, Mikton C, Jones L, Dunne MP. The effect of multiple adverse childhood experiences on health: a systematic review and meta-analysis. Lancet Public Health. 2017;2:e356-66.

23. Miller E, Breslau J, Chung WJ, Green JG, McLaughlin KA, Kessler RC. Adverse childhood experiences and risk of physical violence in adolescent dating relationships. J Epidemiol Community Health. 2011;65:1006-13.

24. Bellis MA, Ashton K, Hughes K, Ford K, Bishop J, Paranjothy S. Adverse childhood experiences and their impact on health-harming behaviours in the Welsh adult population. Cardiff: Public Health Wales; 2015.

25. Ford K, Butler N, Hughes K, Quigg Z, Bellis MA. Adverse childhood experiences (ACES) in Hertfordshire, Luton and Northamptonshire. Liverpool: Liverpool John Moores University; 2016.

26. Musa S, Peek-Asa C, Jovanovic N, Selimovic E. Association of adverse childhood experiences and health risk behaviours among young adults visiting a regional primary healthcare center, Federation of Bosnia and Herzegovina. PLoS One. 2018;13(3):1-14.

27. Whitfield CL, Anda RF, Dube SR, Felitti VJ. Violent childhood experiences and the risk of intimate partner violence in adults: assessment in a large health maintenance organization. J Interpersonal Violence. 2003;18(2):166-85.

28. Ports KA, Ford DC, Merrick MT. Adverse childhood experiences and sexual victimization in adulthood. Child Abuse Negl. 2016;51:313-22.

29. Scottish Government. Delivering for today, investing for tomorrow: the Government's programme for Scotland 2018-2918. Edinburgh: The Scottish Government; 2018.

30. Future Generations Commissioner for Wales, "Adverse childhood experiences," Future Generations, 2020. [Online]. Available: https:// futuregenerations.wales/priority_areas/adverse-childhood-experiences/. [Accessed 7 Jan 2020]. 
31. Berens AE, Jensen SKG, Nelson CA. Biological embedding of childhood adversity: from physiological mechanisms to clinical implications. BMC Med. 2017; 15:e135.

32. Ford JD, Delker BC. Polyvictimization in childhood and its adverse impacts across the lifespan: introduction to the special issue. J Trauma Dissociation 2018;19(3):275-88.

33. Bentall RP, Wickham S, Shevlin M, Varese F. Do specific early-life adversities lead to specific symptoms of psychosis? A study from the 2007 The Adult Psychiatric Morbidity Survey. Schizophr Bull. 2012;38(4): 734-40.

34. Office for National Statistics, Crime Survey for England and Wales, 2015-16 [data collection], vol. SN: 8140. London: UK Data Service; 2020.

35. Office for National Statistics. User guide to crime statistics for England and Wales. London: Office for National Statistics; 2019.

36. TNS-BMRB. Crime survey for England and Wales 2015/16: technical report, volume one. London: Office for National Statistics; 2016. [Online]. Available: https://www.ons.gov.uk/file?uri=/peoplepopulationandcommunity/ crimeandjustice/methodologies/crimeandjusticemethodology/ csewtechnicalreport2016.pdf Accessed 6 July 2019.

37. Bates A. Methodology used for producing ONS's small area population estimates. Popul Trends. 2006;125:30-6.

38. Office for National Statistics. Improving crime statistics for England and Wales - progress update October 2017. London: Office for National Statistics; 2017.

39. Gill B. The English indices of deprivation 2015. London: Department for Communities and Local Government; 2015.

40. Welsh Government. Welsh index of multiple deprivation (WIMD) 2014 Cardiff: Welsh Government; 2014

41. Ministry of Housing, Communities and Local Government.The English indices of deprivation 2019: frequently asked questions (FAQs). London: Ministry of Housing, Communities and Local Government; 2019.

42. Chartier MJ, Walker JR, Naimark B. Separate and cumulative effects of adverse childhood experiences in predicting adult health and health care utilization. Child Abuse Negl. 2010;34:454-64.

43. Grasso DJ, Dierkhising CB, Branson CE, Ford JD, Lee R. Developmental patterns of adverse childhood experiences and current symptoms and impairment in youth referred for trauma-specific services. J Abnorm Child Psychol. 2016:44(5):871-86.

44. Wong CF, Clark LF, Marlotte L. The impact of specific and complex trauma on the mental health of homeless youth. J Interpersonal Violence. 2016; 31(5):831-54.

45. Arata CM, Langhinrichsen-Rohling J, Bowers D, O'Farrill-Swails L. Single versus multi-type maltreatment. J Aggress Maltreat Trauma. 2005;11(4):29-52.

46. van der Kolk BA. Developmental trauma disorder. Psychiatr Ann. 2005;35(5): 401-8.

47. Dvir Y, Ford JD, Hill M, Frazier JA. Childhood maltreatment, emotional dysregulation, and psychiatric comorbidities. Harvard Review Psychiatry. 2014;22(3):149-61.

48. Shipman K, Zeman J, Penza S, Champion K. Emotion management skills in sexually maltreated children and its implications for research, treatment, and policy. Dev Psychopathol. 2001;13:539-64.

49. Bell KM, Higgins L. The impact of childhood emotional abuse and experiential avoidance on maladaptive problem solving and intimate partner violence. Behavioral Sciences. 2015;5:154-75.

50. Messman-Moore T, Coates AA. The impact of childhood trauma on adult interpersonal cibfklict: the role of early maladaptive schemas and patterns of interpersonal behavior. J Emot Abus. 2007;7:75-92.

51. Shields A, Cicchetti D. Reactive aggression among maltreated children: the contributions of attention and emotion. J Clin Psychol. 1998;27:381-95.

52. van der Kolk BA, Perry JC, Herman JL. Childhood origins of self-destructive behavior. Am J Psychiatr. 1991;148:1665-71.

53. Wilson AE, Calhoun KS, Bernat JA. Risk recognition and trauma-related symptoms among sexually revictimized women. J Consult Clin Psychol. 1999;67:705-10

54. Risser JH, Hetzel-Riggen MD, Thomsen CJ, McCanne TR. PTSD as a mediator of sexual revictimization: the roles of re-experiencing, avoidance, and arousal symptoms. J Trauma Stress. 2006;19(5):687-98.

55. Farrell AD, Danish SJ. Peer drug associations and emotional restraint: causes or consequences of adolescents' drug use? J Consulting Clin Psychol. 1993; 61(2):327-34.
56. McPherson M, Smith-Lovin L, Cook JM. Birds of a feather: homophily in social networks. Annu Rev Sociol. 2001;27:415-44.

57. Childs KK, Cochran JK, Gibson CL. Self-control, gang membership, and victimization: an integrated approach. J Crime Justice. 2009;32(1):35-60.

58. Klamuss $\mathrm{D}$. The intergenerational transmission of marital aggression. J Marriage Fam. 1984:46:11-9.

59. Breitenbecher $\mathrm{KH}$. Sexual revictimization among women: a review of the literature focusing on empirical investigations. Aggress Violent Behav. 2001; 6:415-32.

60. Fergusson DM, Horwood LJ, Lynskey MT. Childhood sexual abuse, adolescent sexual behaviours and sexual revictimization. Child Abuse Negl. 1997;21:789-803.

61. Fargo JD. Pathways to adult sexual revictimization: direct and indirect risk factors across the lifespan. J Interpersonal Violence. 2009;24(11):1771-91.

62. Mair C, Cunradi CB, Todd M. Adverse childhood experiences and intimate partner violence: testing psychosocial mediational pathways among couples. Ann Epidemiol. 2012:22(12):832-9.

63. Finkelhor D. Screening for adverse childhood experiences (ACEs): cautions and suggestions. Child Abuse Negl. 2018;85:174-9.

64. Bellis MA, Hardcastle K, Ford K, Hughes K, Ashton K, Quigg Z, Butler N. Does continuous trusted adult support in childhood impart life-course resilience against adverse childhood experiences - a retrospective study on adult health-harming behaviours and mental well-being. BMC Psychiatry. 2017; 17(1):1-12.

65. Dubowitz H, Lane WG, Semiatin JN, Magder LS. The SEEK model of pediatric primary care: can child maltreatment be prevented in a low-risk population? Acad Pediatr. 2012;12(4):259-68.

66. Dubowitz $H$. The safe environment for every kid model: promotion of children's health, development, and safety, and prevention of child neglect. Pediatr Ann. 2014:43(11):e271-7.

67. Olds DL. The nurse-family partnership: an evidence-based preventive intervention. Infant Ment Health J. 2006:27(1):5-25.

68. Follette VM, Polusny MA, Bechtle AE, Naule AE. Cumulative trauma: the impact of child sexual abuse, adult sexual assault, and spouse abuse. J Trauma Stress. 1996;9(1):25-35.

69. Briere J, Jordan CE. Violence against women: outcome complexity and implications for assessment and treatment. J Interpersonal Violence. 2004; 19(11):1252-76.

70. van Kesteren J, van Dijk J, Mayhew P. The international crime victims surveys: a retrospective. Int Review Victimol. 2014;20(1):49-69.

71. Office for National Statistics, "The nature of violent crime in England and Wales: year ending 2018," 7 February 2019. Available: https://www.ons.gov. uk/peoplepopulationandcommunity/crimeandjustice/articles/ thenatureofviolentcrimeinenglandandwales/yearendingmarch2018\#whichgroups-of-people-are-most-likely-to-be-victims-of-violent-crime. [Accessed 8 Dec 2019].

72. Walby S, Towers J, Francis B. Is violent crime increasing or decreasing? A new methodology to measure repeat attacks making visible the significance of gender and domestic relations. Brit J Criminol. 2015;56(6): 1203-34.

73. Arata CM. Repeated sexual victimization and mental disorders in women. J Child Sexual Abuse. 1999;7:1-17.

74. Cloitre M, Scarvalone P, Difede J. Posttraumatic stress disorder, self- and interpersonal dysfunction among sexually retraumatized women. J Trauma Stress. 1997:10:437-52.

75. Messman-Moore TL, Long PJ, Siegfried NJ. The revictimization of child sexual abuse survivors: an examination of the adjustment of college women with child sexual abuse, adult sexual assault, and adult physical abuse. Child Maltreatment. 2000;5:18-27.

76. Kilpatrick DG, Acierno R, Resnick HS, Saunders BE, Best CL. A 2-year longitudinal analysis of the relationship between violent assault and substance use in women. J Consult Clin Psychol. 1997:65(5):834-47.

77. Christiaens I, Hegadoren K, Olsen DM. Adverse childhood experiences are associated with spontaneous preterm birth: a case-control study. BMC Medicine. 2015;13(124):1-9.

78. Pachter LM, Lieberman L, Bloom SL, Fein JA. Developing a community-wide initiative to address childhood adversity and toxic stress: a case study of the Philadelphia ACE Task Force. Acad Pediatr. 2017:17(7S):S130-5.

79. Substance Abuse and Mental Health Services Administration. SAMHSA's concept of trauma and guidance for a trauma-informed approach. Rockville: Substance Abuse and Mental Health Services Administration; 2014. 
80. Bellis M, Hughes K, Hardcastle K, Ashton K, Ford K, Quigg Z, Davies A. The impact of adverse childhood experiences on health service use across the life course using a retrospective cohort study. J Health Services Res Polic. 2017;22(3):168-77.

81. Brown J, King M, Wissow L. The central role of relationships with traumainformed integrated care for children and youth. Acad Pediatr. 2017;17(7): S94-S101.

82. Sethi $D$, Bellis M, Hughes $K$, Gilbert R, Mitis F, Galea G. European report on preventing child maltreatment. Copenhagen: World Health Organization; 2013.

83. UN, "Transforming our world: the 2030 agenda for sustainable development. Resolution adopted by the general Assemby on 25 September 2015: A/RES/70/1," United Nations, New York, 2015.

84. Daelmans B, Darmstadt GL, Lombardi J, Black MM, Britto PR, Lye S, Dua T, Bhutta ZA, Richter LM. Early childhood development: the foundation of sustainable development. Lancet. 2016;389(10064):9-11.

85. Fisher HL, Schreier A, Zammit S, Maughan B, Munafo MR, Lewis G, Wolke D. Pathways between childhood victimization and psychosis-like symptoms in the ALSPAC birth cohort. Schizophr Bull. 2012;39:1045-55.

86. Connolly EJ. Further evaluating the relationship between adverse childhood experiences, antisocial behavior, and violent victimization: a sibling comparison analysis. Youth Violence Juvenile Justice. 2019;18(1):3-23.

87. Edalati H, Nicholls TL, Crocker AG, Roy L, Somers JM, Patterson ML. Adverse childhood experiences and the risk of criminal justice involvement and victimization among homeless adults with mental illness. Psychiatr Serv. 2017:68(12):1288-95.

88. De Bellis MD, Zisk A. The biological effects of childhood trauma. Child Adolesc Psychiatr Clin N Am. 2014;23(2):185-222.

89. Levenson J. Adverse childhood experiences and subsequent substance abuse in a sample of sexual offenders: implications for treatment and prevention. Victims Offenderes. 2016;11(2):199-224.

90. Schalinski I, Teicher MH, Nischk D, Hinderer E, Muller O, Rockstroh B. Type and timing of adverse childhood experiences differentially affect severity of PTSD, dissociative and depressive symptoms in adult inpatients. BMC Psychiatry. 2016;16(295).

91. Larkin H, Park J. Adverse childhood experiences (ACEs), service use, and service helpfulness among people experiencing homelessness. Fam Soc 2012;93(2):85-93.

92. Font SA, Maguire-Jack K. Pathways from childhood abuse and other adversities to adult health risks: the role of adult socioeconomic conditions. Child Abuse Negl. 2016;51:390-9.

93. Adams J, Mrug S, Knight DC. Characteristics of child physical and sexual abuse as predictors of psychopathology. Child Abuse Negl. 2018;86:167-77.

\section{Publisher's Note}

Springer Nature remains neutral with regard to jurisdictional claims in published maps and institutional affiliations.

Ready to submit your research? Choose BMC and benefit from:

- fast, convenient online submission

- thorough peer review by experienced researchers in your field

- rapid publication on acceptance

- support for research data, including large and complex data types

- gold Open Access which fosters wider collaboration and increased citations

- maximum visibility for your research: over $100 \mathrm{M}$ website views per year

At $\mathrm{BMC}$, research is always in progress.

Learn more biomedcentral.com/submissions 